\title{
LA BEAUTÉ, LA SOLITUDE LA BELLEZA, LA SOLEDAD
}

Il dit : la solitude a des ombres et des cris de pigeons. Une odeur rance d'arrière-cour. Une chambre au lit défait où les nuits se suivent et sont interminables. Elle ressemble au même visage qui dans la glace, au matin, ne se reconnaît plus.

Dice él: la soledad tiene sombras y gritos de palomas. Un olor rancio a patio trasero. Una habitación con la cama sin hacer en la que las noches se suceden y son interminables. Se parece a ese rostro que en el espejo, por la mañana, ya no se reconoce.

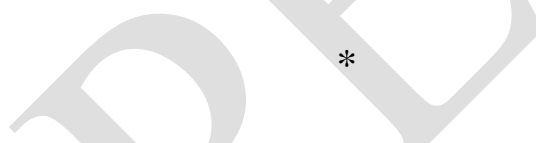

Il dit : la beauté tombe de là-haut. Son index se lève. Dans les feuilles, les heures, dans les yeux. Elle ne cesse de tomber. On la voit bien. Mais personne pour la ramasser.

Dice él: la belleza cae de allá arriba. Levanta el dedo índice. En las hojas, las horas, en los ojos. No deja de caer. Se ve con claridad. Pero no hay nadie que la recoja.

Il dit : la solitude ressemble à un café où ceux qui entrent croient sortir ou ceux qui sortent restent sans le savoir. Elle a des tables, des verres, des voix - des éclats de rire. Elle a un percolateur sonore et rutilant qui ne réussit pas à éclairer les recoins où se réfugie l'ombre. Elle a au centre un grand vide éblouissant où tombent et s'effacent les visages.

Dice él: la soledad se parece a un café en el que los que entran creen que salen o los que salen se quedan sin saberlo. Tiene 
mesas, vasos, voces - carcajadas. Tiene una cafetera sonora y rutilante que no logra alumbrar los recovecos donde se cobija la sombra. Tiene en el centro un gran vacío deslumbrante donde se caen y se borran los rostros.

Et que la beauté t'entre encore dans les yeux — c'est lui toujours. Avec sa double raie de feu, ses falaises étincelantes, son vent soudain visible. Avec ce qui t'emporte et te déchire - et te laisse sans visage.

Y que la belleza te entre de nuevo por los ojos - de nuevo es él quien habla. Con su doble raya de fuego, sus acantilados relumbrantes, su viento visible de repente. Con lo que te arrebata y te desgarra - y te deja sin rostro.

La solitude. Une pause. La solitude te fixe de ses yeux vides. Tu vois la porte se fermer. Tu vois la table avec la chaise - le fauteuil, peut-être. Tu vois, mortes sur la vitre, les faces de béton ou les feuilles, c'est pareil. Tu fermes les yeux mais tu vois, malgré tout. Il soupire longuement. Tu vois tous les visages qui s'en vont et, dans le miroir, celui que tu as trop vu.

La soledad. Una pausa. La soledad te mira fijamente con los ojos vacíos. Ves cerrarse la puerta. Ves la mesa con la silla - o el sillón, tal vez. Ves, muertas sobre el cristal, las caras de hormigón o las hojas, es lo mismo. Cierras los ojos, pero, a pesar de todo, sigues viendo. Suspira él largamente. Ves todos los rostros que se marchan y, en el espejo, ese otro que tienes ya demasiado visto.

Il dit : la beauté, là, tout près. Il tend la main. Là. La montagne est une fumée qui monte. Une buse crie, le vent remue les feuilles. Il répète : là, tout près. Sa main se perd dans la lumière.

Dice él: la belleza, ahí, muy cerca. Tiende la mano. Ahí. La montaña es un humo que sube. Un cernícalo grita, el viento agita las hojas. Repite: ahí, muy cerca. Su mano se pierde en la luz. 
Il tousse. Regarde l'implacable lumière, le tuyau, le noisetier. Reprend son souffle. Ouvre la bouche. Mais rien n'en sort. Sauf, peut-être, un mélange d'air et de feu. Un silence lointain où vient se former comme un mot qu'on pourrait presque comprendre.

Tose él. Y mira la implacable luz, el tubo, el avellano. Y recupera el aliento. $Y$ abre la boca. Pero no sale nada. Salvo, tal vez, una mezcla de aire y de fuego. Un silencio lejano en el que se va formando una suerte de palabra que casi se podría entender.

La solitude — tu ne sais pas. Ou tu sais mais tu as oublié. La porte claque, les pas s'éloignent. La lumière devient un nom, et l'espace le temps. Tu ne vois pas plus loin que ton corps. Le cercle des choses se referme, te touche, t'écrase presque. Non, tu ne sais pas.

La soledad - no lo sabes. O lo sabes, pero lo has olvidado. La puerta se cierra de golpe, los pasos se alejan. La luz se convierte en un nombre, y el espacio en el tiempo. No ves más allá de tu cuerpo. El círculo de las cosas ya se cierra, te toca, casi te aplasta. No, no lo sabes.

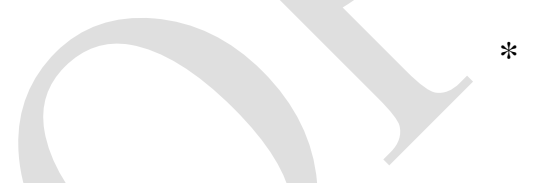

Et la beauté encore qui te traverse de sa douceur - te blesse, te brûle. Et comment faire pour y être, demande-t-il, comment ? Son visage se tourne vers le jour, s'obscurcit de tant de lumière. La beauté où ton corps n'entre pas, reste sur le seuil, vacille, tombe dans l'ombre.

Y la belleza de nuevo atravesándote con su suavidad - te hiere, te quema. ¿Qué hacer para poder estar ahí?, pregunta él, ¿qué? Su rostro se vuelve hacia la claridad, se oscurece con tanta luz. La belleza donde tu cuerpo no entra, se queda en el umbral, se tambalea, cae en la sombra.

Del libro inédito Le maître d'ignorance

Traducción de Clara CURELL (Universidad de La Laguna) y Claire Laguian (Université de Paris-Est Marne-la-Vallée) 